\title{
The portrait of older people as (non) users of digital technologies: A scoping literature review and a typology of digital older (non) users
}

\author{
Sofia Alexopoulou MS ${ }^{a, *}$ \\ ${ }^{a}$ PhD candidate in the department of Political Science, Program of Successful Ageing, Uni- \\ versity of Örebro, Örebro, Sweden; *Corresponding author: sofia.alexopoulou@oru.se
}

\begin{abstract}
Background: The images of older people while using (or not) technology is a theme that plays a crucial role not only in the implementation of policies, but also in the design of eservices or more broadly e-governance. Older people is a complex and a non-homogenous group that requires public (welfare) services which in many cases have been moved to a digital interface. The real challenge is to provide these services without excluding anyone. Objective: This paper aims to investigate how older people are represented as (non)users of technology in the digital literature and public discourse and to produce a typology of older digital users based on the work of Schneider and Ingram (1993).

Method: The study followed established methods for a scoping literature review to discover the profile of older digital (non) users and their relationship with technology.

Results: Based on this literature review, two positive profiles of different power were found: the silver surfers or "athletes" who are proficient digital users and the "older people with borrowed access" to digital technologies who are less powerful and independent while using technology. On the other hand, we also found some negative images of older adults: the "laidback" who are reluctant to use digital technologies but they have the necessary intellectual capacity to acquire IT skills on their own (strong in terms of power). The biggest group entails older people as technophobic, non-users, want-nots, digitally backward/internet laggards, digital immigrants, needy and those who are unaware of their digital condition. Conclusion: This research could offer a substantial contribution to policy-makers and public servants to provide better and friendlier online services, digital tools and applications in conjunction with the supply of IT courses for older individuals.
\end{abstract}

Keywords: grey digital divide, older people, ICTs, internet, public policy

\section{INTRODUCTION}

The political objective of all governments is to prevent the growth of the digital divide - a notion referring to the gap between those with and those without access to new forms of information and communication technologies (Van Dijk, 2006). Though the term has pervaded the current digital literature, there is no universally accepted definition of the phenomenon. Gunkel (2003, p 504) argues that the digital divide:

"not only names different kinds of technological and social differences but, even when it appears to refer to the same object, [it] does so differently at different times and in different contexts."

Therefore, the notion of the digital divide is of a variating nature. Based on Gunkel's definition of the digital divide, the concept has acquired the features of a "wicked problem". More precisely, the digital divide falls under the category of public policy/social issues, which, in most cases, are "illdefined" in comparison to natural-science problems that can be "definable", "separable" and "may have solutions that are findable" (Rittel and
Webber, 1973, p.160). Handling socio-political problems of this kind are difficult and it is dependent on "elusive political judgment for resolution" (Rittel and Webber, 1973, p. 160). These social problems are never entirely addressed. Instead, they are repeatedly resolved (Rittel and Webber, 1973) by different actors in the political arena.

The review aimed to address the research question: How are older people represented as digital (non)users of technology (ICT's and the Internet) in digital literature and public discourse?

The research gap is that no one has tried to produce a specific typology of different older digital (non)users based on the way these individuals are depicted in the current literature and public discourse. With this information in mind, our key challenge is to present the profile of older individuals in relation to digital technologies and to see how the state should intervene depending on the target population. Our point of departure is the paper of Schneider and Ingram (1993). We strongly contend that defining a situation or 
an individual as close to reality as possible is of paramount importance since "the way in which a particular problem is defined leads to a specific policy solution" (Servon 2002, p.8).

To familiarize readers with this paper, an outline is provided: We begin with some background information regarding the grey digital divide and we explain the reasons why digital technologies are increasingly important for older people. As we understand it, the grey digital divide labels the difficulties/obstacles of elders, when using digital technologies. The second section is dedicated to the conceptual framework of Schneider and Ingram (1993) and the applied methodology of this study. The third section highlights, the varied images ascribed to older people as (non)users of digital technologies. The paper ends with a discussion and the conclusions, by arguing that the digital chasm is not irreversible if appropriate policies are implemented -in particular as regards the weaker links of the digital pendulum. In particular, the state should enhance the digital literacy of older people who are mostly named as technophobic, non-users, want-nots, digitally backward/ internet laggards, digital immigrants, needy, and those who are unaware of their digital conditionespecially, if the latter wish to use technology.

\section{BACKGROUND INFORMATION: KEY CONCEPTS From the digital divide to the grey digital di- vide problem}

The term "digital divide" was coined in the 1990s as a binary concept between the "haves" and "have-nots" of technology, but in reality, it goes much beyond that division. Today, the term signifies the "gap between those who do and who do not enjoy the benefits of access to the Internet" (Olphert and Damodaran, 2013, p. 565) or as Tsasou (2011, p.327) insightfully pinpoints: (1) Digital divides should be viewed within a complex context where decision-makers' problem-solving and other practices meet and interact with ordinary people's attitudes and live cultures. In consequence, the digital divide constitutes a multi-dimensional problem (Norris, 2001) which is bounded to the context of a country (technological culture, technological development, and so on) and the characteristics of its citizens.

Traditional digital divide literature emphasizes the importance of demographic and socioeconomic factors, such as gender divide, income divide, etc. as the main determinants of the divide (Ferro et al., 2011), In this way, the emphasis is mostly paid on the characteristics of individuals. Other scholars take a different approach (a multi-perspective or emergent view). They reject the idea that individual groups materialize digital technologies differently than the majority. However, they accept that "individuals and com- munities employ technologies for very specific goals, linked often to their histories and social locations" (Hines, Nelson, and Tu, 2001, p. 5) and that "barriers to access operate on many levels and therefore solutions must take multiple approaches" (Hines, Nelson, and Tu, 2001, p. 5). A very interesting example is the study of Milioni et al. (2014) in Cyprus, which showed the existence of a "reverse digital divide", according to which the most un-favorable community (low salary, less educated and women) uses the internet more frequently compared to the more-favored communities and as a medium of expression, association, and learning.

A group often locked in the digital divide trap consists of digital non-users of older age (Eynon and Helsper, 2011; Niehaves and Plattfaut, 2014). Said group seems to lag as regards the uptake/usage of digital technologies compared with other groups and particularly younger generations (Anderson and Perrin, 2017; Comunello et al., 2016; Neves et al., 2013; Van Dijk, 2005). This recognition is a threat to electronic inclusion - a priority on the European political agenda since the Riga Declaration in 2006.

Under this prism, governments develop policies to combat the digital divide for two key reasons: First, to attain economic growth or innovation and secondly to reduce the level of inequality or promote social inclusion (Van Dijk, 2008). The first reason, according to Van Dijk (2008), is by far more important for governments. In reality, though, it is extremely difficult for someone to make a distinction between the first and the second goal because both are equally important in achieving economic and social growth.

As the term was introduced a long time ago (1998), much ink has already been spilled on analyzing the digital divide problem and its various levels (see the systematic literature review held by Scheerder, Van Deursen, and Van Dijk, 2017). The digital divide was initially considered a material-physical access issue relating, for example, to the ability of an individual to buy a computer, establish a home Internet connection, or even have a telephone line (i.e., the first-level digital divide, see the NTIA reports, 1998, 1999). Then, it was approached as a problem concerning the lack of skills (i.e., the second-level digital divide, Hargittai, 2002). The missed outcomes or opportunities that occur due to exclusion from the digital world were later considered the third-level of digital divide (Wei et al., 2011, Van Deursen and Helsper 2015a). Since the 2000s, many studies have replaced the term "digital divide" with more perplexed and multi-layered approaches to digital inclusion (Tsatsou et al., 2017). 
Relevant to the knowledge block of the digital divide problem is another term called the "grey digital divide". The grey digital divide was coined for the first time in 2003 and refers to the low use of the internet by older adults (Millward, 2003) or to put it, in other words, the exclusion of older people from the internet (Table 1). The main reasons for this internet lie in a combination of reasons, summarized in various parts of the existing literature (Millward, 2003; Morris and Brading, 2007), such as:

Table 1. Grey digital divide: Basic obstacles for seniors' digital inclusion.

- lack of interest, motivation,

- lack of e-literacy,

- lack of skills,

- apathy,

- cost of equipment,

- feelings of 'oldness',

- technophobia,

- obstacles in having access to IT such as having concerns about security and privacy,

- $\quad$ physical/health issues like disability

However, studies show that the digitally disadvantaged are also socially disadvantaged in many cases (Granjon, 2009; Lüders and Gjevjon, 2017). Thus, the socially rich get socially richer with the use of digital technologies.

For older people, the digital divide is much more complicated, as those forming part of the senior (senior aged 75+ years) may encounter serious health problems in comparison to younger individuals, which could disqualify them from social participation and its digital counterpart. According to Friemel (2016, p. 325) "every second senior of age 85 years and older is not using the Internet due to limited eyesight or hearing, with one-quarter mentioning dexterity issues". However, according to a different view, old age is not likely to cause digital disengagement (Gilleard and Higgs, 2008). On the contrary, older people born during or just after the Second World War and raised during the emergence of a mass consumer society, have more chances to participate in every aspect of this new consumer culture, including the digital realm (Gilleard and Higgs, 2008).

Yet another remarkable fact is that previous use of technology can play a role in the uptake of technology, especially after retirement. Someone who used a computer in the workplace before retirement spends nine times more time online than those who did not use computers in the workplace (Friemel, 2016, p. 325). On the contrary, Selwyn's (2004) research showed that many individuals who had used computers at work decided to refrain from them during retirement. This contradicting result implies that the use of digital technologies after retirement is a personal choice that differs from one person to the other and could be based on a number of explanations if someone attempted to delve into the individual stories.

In parallel, Loges and Jung (2001) mention that according to a substantial body of literature it is normal for seniors to undergo disengagement and that it may sometimes be detrimental to push seniors to use the internet to restore previous social ties. As their friends and relatives die, seniors avoid developing new friendships, because there is insufficient time for them to attain the same depth (Loges and Jung, 2001). This suggests that digital disengagement may not always convey a negative impact on the lives of seniors since it is a natural process related to aging per se.

Cultural factors and personal preferences may also shed light on certain patterns of ICT and the internet in relation to older individuals. For instance, in Portugal, active seniors did not use the internet to make new friends or find individuals with the same interests/habits as them, nor did they find it easier to express their thoughts via the internet. Rather, these seniors alleged that they valued face-to-face interaction more, seeing the internet as an instrument helping them to preserve existing friendship ties (Martinez-Pecino et al. 2013). Likewise, Quan-Haase et al. (2017, p. 979) discovered that older people consider email an important tool for obtaining support from friends and family near and far, but still regard the telephone as a "preferred choice" based on its usability and familiarity, though second to in-person contact. So again human interaction comes first as a choice among older people.

To sum up, the grey digital divide concept has been very useful. From the time when the term was incepted in 2003, the grey digital divide problem has attracted much attention and continues to be at the center of a heated academic debate. The term recognized seniors as a unique and separate social group as regards their access and usage of the internet while pointing out the generational gap that exists between young and old people in the acceptance-adoption of technology. The concept of the grey digital divide keeps evolving and broadening with new technological developments, while it takes diverse forms, as exactly the aging process which is a heterogeneous, multidimensional process (Beimborn et al., 2016).

\section{Why technology is increasingly important for older people?}

More than ever before, the digitally advanced states provide the aging population with a wide digital selection of welfare benefits and health 
services (telecare), to an extent that some authors speak about the rise of a big brother or a brave new world (Percival and Hanson 2006). It must be noted that in many western nations digital welfare services for the well-being of elders are of high priority on the political agenda for this segment of the population. All these new eservices are based on distance and encourage citizens to minimize their contact with streetlevel public administration (Lipsky, 1980). The advertised benefits of digital service delivery are the rise of transparency/accountability, the reduction of red tape, the creation of a 'paperless state', and the saving of scarce financial resources (Bygstad and Lanestedt, 2017, p.287).

The interaction between the State and citizens with the usage of digital technologies had gained considerable momentum as a new policy tool for the innovation of the public healthcare sector in Scandinavia where the term "welfare technologies" was developed. Welfare technologies encompass: "demographic developments, the restructuring of the welfare system and the expansion of the IT infrastructure. The definition of welfare technology has evolved from being just the application to including the application, system and administration of service" (Östlund et al., 2015, p.3).

This means that today welfare technologies or digital welfare technologies or gerotechnologies (these terms are interchangeable) assist in the delivery of welfare services to citizens with the usage of technology that is not limited to the field of health care (see for instance the online delivery of pension services, Breit and Salomon, 2015). Older people are in great need of these welfare services in order to maintain their quality of life and independent living. However, the fully implemented version of e-government may eventually cause new marginalizing effects for the digitally disengaged (Siren and Knudsen, 2017, p.37).

Broadly speaking, the seniors today are expected to follow the dominant technological culture and to actively engage in the cyber-space. This 'push' towards digital technologies complies entirely with the neoliberal and active-aging agenda disseminated in many countries -if not all-, according to which older individuals are no longer perceived as irrefutable recipients of (welfare) services, but must demand said services energetically. As denoted by Van Dyk (2014, p.95): "the promotion of active-ageing principles is not just a welcome acknowledgement of older people and their potential but concurrently approves of neoliberal welfare state restructuring: basic principles of the active-ageing-paradigm - in particular the individualization of risk and achievement - are diagnosed as key concepts of a new social policy that combines political rhetoric of welfare state maintenance with a political practice of social cutbacks."

The concept of active aging is gaining more and more ground in Europe. The concept refers to the idea of longer-lasting activities, which extend to every aspect of life, including the social engagement of older adults in society and their political engagement (Forster and Walker, 2014). Despite the negative connotation associated with it, active aging is a positive term in gerontology studies. It combines the benefits of physical and social activities and is perceived as a method to fight against illness, loneliness, disability, and trauma (Katz, 2000, p.136). Active aging is vigorously associated with bodily exercise, which, in later life, provides substantial psychological and physical benefits, ultimately reducing the state's financial burden of a growing and dependent aging population (Wheaton, 2017, p.98) or triggers the unreachable dream of aging without aging (Katz, 2005). This is why active aging ideas have been extensively accepted and promoted by governments, despite the fact that they are not suitable for all (see for instance the cases of Alzheimer patients) or tend to ignore that some people wish to withdraw from society and its digital counterpart (social and digital disengagement).

\section{THEORETICAL UNDERPINNINGS}

This article proposes the study of the digital divide problem among older people as a policy/ welfare problem. On a general level, policymakers and public servants place individuals into various categories. This, in our view, is done as a means to justify certain policy choices, like the allocation of scarce financial resources or political preferences for satisfying the interests of specific social groups (clientelism). A tool in doing so is social constructions which constitute a common tactic in reducing the complexity of the policy-making process by categorizing citizens either positively (i.e. "deserving") or negatively (i.e. "undeserving") of the state's assistance (Schneider and Ingram, 1993, p.335).

The social constructions or otherwise the representations of a target population denote "the cultural characterizations or popular images of the persons or groups whose behavior and well-being are affected by public policy" (Schneider and Ingram, 1993, p.334). Each social construction brings together two key elements: first the recognition of some commonly shared characteristics, which clearly distinguish the target group at hand from the other social groups and second the language used, which tends to impose certain values on individuals (Schneider and Ingram, 1993, p.335).

For the aim of this paper, we direct our attention to the key images of older people in litera- 
Table 2. The four types of social constructions.

Positive social construction

Strong in terms

of power
Advantaged are perceived as powerful and

demonstrate a positive construction.

\section{Negative social construction}

Contenders are seen as powerful but

demonstrate a negative construction.

Weak in terms Dependents are politically weak and in general Deviants are weak and are accompanied

of power

ture and public discourse as regards the uptake of digital technologies without claiming in advance that these images are necessarily social constructions. The starting point of our analysis is the categorization matrix of Schneider and Ingram (1993). Social constructions are classified into four types/categories: (1) the "advantaged", who are perceived as powerful, demonstrate a positive construction and are in a powerful position; (2) the "dependents", who are politically weak and generally demonstrate a positive construction; (3) the "contenders", who are seen as powerful, but demonstrate a negative construction; and finally (4) the "deviants", who are both weak and accompanied by a negative construction. For each category, Schneider and Ingram put different social groups. For our scoping literature review, we focus on older people, exclusively. Table 2 depicts Schneider and Ingram's (1993, p.336) social constructions scheme for the target group(s) of a policy.

The target group internalizes the messages and experiences the results of the implemented digital policy. This, in simple words, implies that the social constructions exercise power and regulate the individual's identity in terms of access to public goods (eligibility criteria), political participation (active versus passive) and their overall status as citizens (who is within or outside the rights of citizenship), or to put it differently delineate who is included or excluded.

\section{Methodology}

This article is not a systematic review but a scoping literature review. This scoping review is based on a broader research question in comparison to a systematic literature review, which provides an answer to a very narrow research question (Arksey and O'Malley, 2005). Rather, its objective is to report the scientific evidence in a specific field of knowledge, while summarizing research findings and discovering research gaps. After analyzing the grey digital divide research, in this section of the paper we will seek for the most common representations of older people as 'figures' of the digital world. For that reason, we applied the guidelines of Arksey and O'Malley (2005) and Levac and al (2010):

- We identified the research question.

- We found more relevant studies.

by a negative construction.

- We proceeded with the study selection.

- We conducted the charting of the data and

- We collated, summarized and reported the results.

For performing this literature review a priori inclusion and exclusion criteria were established. Two databases were included for conducting this literature review: (1) Web of Science Database, (2) International Bibliography of the Social Sciences (IBSS) while additional searches were made in Google Scholar. Also, the reference lists of selected articles were reviewed for includable studies. The string applied was: ((grey digital divide OR digital barrier OR digital gap OR Internet access) AND (old people OR older people OR aged OR seniors OR senior citizens)).

The literature spans from 2003 to January 2019 while the geographical distribution was focused primarily on Europe and to other developed countries such as Australia. The year 2003 is not a coincidence since that year the term "grey digital divide" was coined by Millward for describing the low use of the internet by older adults. However, for this literature review, we didn't limit ourselves merely to the usage of the internet but we took into account the digital technologies, in general.

The selected papers had to be published in (1) English language, (2) peer-reviewed academic journals (when it was applicable), (3) between 2003 and January 2019 and (4) to be focused on older people as (non)users of digital technologies in developed societies and (5) user's typology (inclusion criteria). In the Web of Science, we searched the following disciplines Health care science services, computer science information systems, ethics, medical informatics, geriatrics gerontology, humanities multidisciplinary, communication, social work, anthropology, sociology, political science, cultural studies, gerontology, computer science interdisciplinary applications, public administration, health policy services, psychology social, computer science cybernetics, social sciences interdisciplinary and social issues while in the IBSS we searched for Information, Communication \& Society, The American Behavioral Scientist, American Sociological Review, British Journal of Social Work, Journal of Health Communication, Journal of Sociology, Social Science \& Medicine. In our search, 
Table 3. Study flow.

\begin{tabular}{lc}
\hline Step 1 & $\begin{array}{c}\mathrm{N}=4648 \text { articles (4414 Web of Science and 234 IBSS) were initially discovered by only } \\
\text { applying the search string to the databases Web of Science Database and International } \\
\text { Bibliography of the Social Sciences for the selected time period (2003-2019, January). }\end{array}$ \\
$\begin{array}{l}\mathrm{N}=656 \text { potentially relevant full-text articles based on our inclusion-exclusion criteria (647 } \\
\text { Web of Science and 9 IBSS) }\end{array}$ \\
$\begin{array}{l}\text { Final } \\
\text { decision }\end{array}$ \\
$\begin{array}{l}\text { 24 eligible papers came out from the previous databases in conjunction with an additional } \\
\text { search on Google Scholar (complementary) and the references of the retrieved papers. }\end{array}$ \\
\hline
\end{tabular}

younger people and children were not reflected as (non)users of technology and we were not focused on a specific profession such as nursing or organization because we wanted to achieve generalizability (exclusion criteria).

In order to discover relevant scientific publications addressing our topic, a structured approach following the suggestions of Webster and Watson (2002) was adopted: (1) search on the particular keyword(s) in journal databases namely our search string; (2) selection of publications with matching criteria; (3) quick screening of the identified publications by reading their titles, abstracts, and full text to select those relevant to our research; and (iv) detailed process of reading and analyzing a full text of the selected publication. When the publication's title or abstract appeared significant, the full text was quickly looked over to ensure that the content is relevant (Table 3).

The qualified publications were retained in a chronological list and the irrelevant ones were eliminated. Finally, 24 papers (Table 4) were gathered for this literature review. The selected papers were read carefully, notes were taken and were presented in a narrative synthesis with the use of the Schneider and Ingram's matrix (1993). We make no pretense that the literature review is exhaustive but we are certain that contains the most important items.

\section{Results}

Negative social images: Seniors as laidback individuals (strong in terms of power) versus seniors as non-users, want-nots, internet laggards, digital immigrants, technophobic and needy (not so strong in power)

Research on the digital divide, frequently describes seniors as a homogeneous group with uniform reasons for not using technology (Van Deursen and Helsper, 2015b), while it greatly emphasizes on the politically correct labeling of seniors rather than the real consequences of treating this diverse group as homogeneous (Friemel, 2016). Also, many scholarly articles express worries about the segment of senior citizens on the wrong side of the digital divide, i.e., non-users or have-nots. As held by Van Deursen and Helsper (2015b, p. 174) "Adapting the expression of 'have-nots', people who remain on the 'wrong' side of the digital divide because of motivational problems are increasingly referred to as 'want-nots'". Thus they are often described as if they have a choice in the matter. Even worse, older people are often labeled as "digital immigrants" (Prensky, 2009) as opposed to "digital natives", who are mostly younger people with great expertise in the use of digital technologies or that people aged 55 and over will use fewer computers and the Internet than younger people (Morris et al, 2007). The generation effect is apparent as younger people are exposed to computers and the Internet very early in their lives and acquire digital skills during their childhood, while older people tend to embrace digital technologies later in their lives and it is more difficult for them to master new skills.

In addition, certain myths regarding older people and their position in the digital realm are often reproduced. These myths are widespread among computer scientists, engineers, and programmers, as well as among the general public and even older individuals themselves (Table 5). The above myths and stereotypes are usually permeated with the spirit of ageism and their replication is detrimental, reinforcing older people's lack of motivation and confidence in employing new technologies. These statements are "[s]weeping generalisations [that] by their very nature mask differences of opinion and experience, and in that way close down discussions. Generalisations paint over the messy realities of everyday life" (Roberts, 2010, p.4). In short, these generalizations mask the grey digital divide problem and constitute the real problem, since they disorientate the public opinion.

Stated even more bluntly, negative stereotypes are general statements that also act as "self-fulfilling prophecies". This calls to mind Merton's (1948, pp. 195-196) views, according to which falsely defining a certain situation educes new behaviors and can result in the original false conception being fulfilled. In the end, it becomes almost impossible to erase such false conceptions because, in a way, they have become incorporated in older adults as 'cognitive baggage'. The next step in this vicious circle is the continuation of the digital literacy paradox (Schreurs and Quan-Haase, 2017). 
Table 4. Twenty-four (24) papers organized by year.

\begin{tabular}{|c|c|c|c|c|c|c|c|}
\hline \multirow{2}{*}{$\begin{array}{r}2018 \\
\bullet\end{array}$} & \multicolumn{3}{|c|}{2017} & \multicolumn{2}{|l|}{2016} & \multicolumn{2}{|c|}{ 2015b } \\
\hline & $\begin{array}{l}\text { Reneland-Forsman: } \\
\text { Older people with } \\
\text { borrowed access }\end{array}$ & & $\begin{array}{l}\text { Schreurs and Quan- } \\
\text { Haase: Older } \\
\text { people's digital } \\
\text { literacy paradox }\end{array}$ & & $\begin{array}{l}\text { Friemel: Older } \\
\text { people is not a } \\
\text { homogenous group. } \\
\text { The labeling and the } \\
\text { treatment of this } \\
\text { group matters } \\
\text { Ivan and Schiau: } \\
\text { Older people's } \\
\text { "stereotype threat" }\end{array}$ & & $\begin{array}{l}\text { Van Deursen and } \\
\text { Helsper: "Have-nots } \\
\text { " and "want-nots" }\end{array}$ \\
\hline 2014 & & & & 2011 & & & \\
\hline$\bullet$ & $\begin{array}{l}\text { Niehaves \& } \\
\text { Plattfaut: Older } \\
\text { people are often } \\
\text { lagging behind in } \\
\text { digital terms } \\
\text { Mariën and } \\
\text { Prodnik: } \\
\text { Divergence from } \\
\text { the digital norm of } \\
\text { a given society }\end{array}$ & & $\begin{array}{l}\text { Wandke, Sengpiel, } \\
\text { and Sönksen: } \\
\text { Multiple myths } \\
\text { related to older } \\
\text { people and } \\
\text { technology } \\
\text { Neves and Amaro: } \\
\text { Older people as } \\
\text { technophobic }\end{array}$ & $\bullet$ & $\begin{array}{l}\text { Ferro et al.: Older } \\
\text { digital users as } \\
\text { athletes, laidback } \\
\text { and needy } \\
\text { Brandtzæg et al.: } \\
\text { Different categories } \\
\text { of digital (non)users. } \\
\text { Older people are } \\
\text { mostly "instrumental } \\
\text { users", "sporadic } \\
\text { users" and "non- } \\
\text { users". }\end{array}$ & & $\begin{array}{l}\text { Choudrie et al.: } \\
\text { "Silver-surfers" as the } \\
\text { majority of } \\
\text { broadband users }\end{array}$ \\
\hline
\end{tabular}

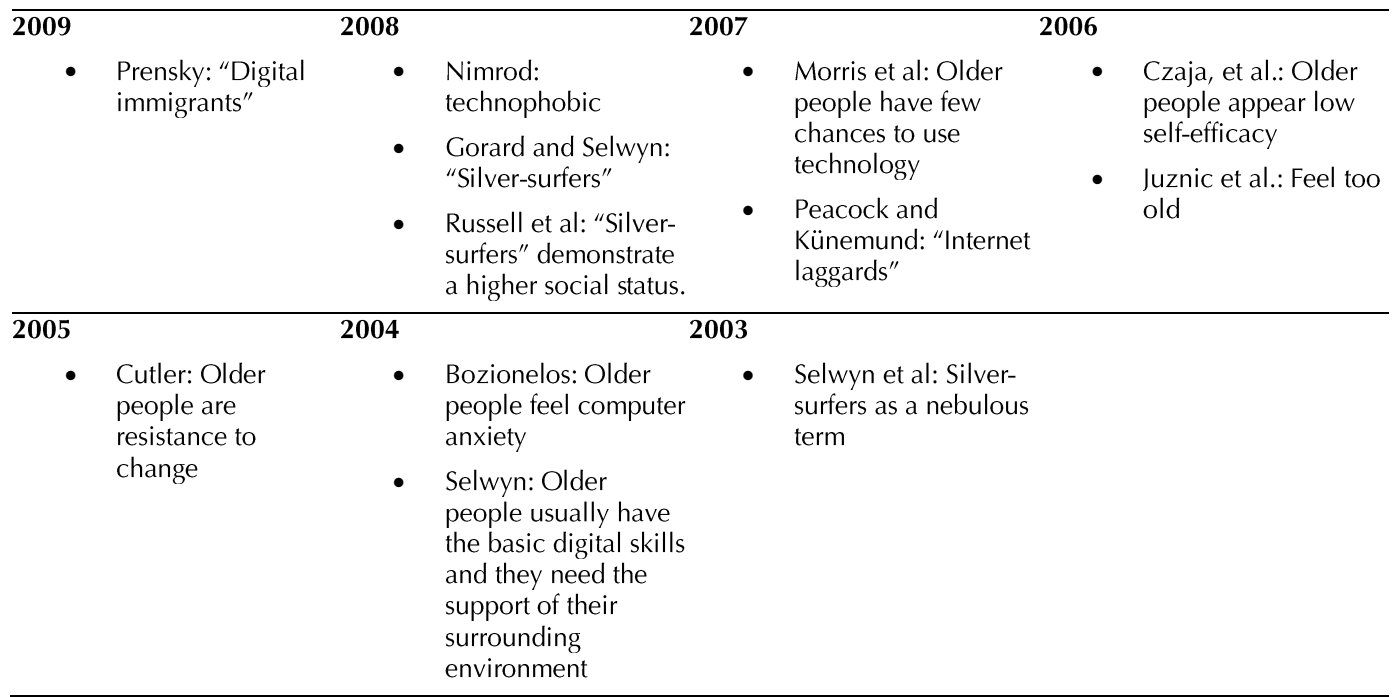

The digital literacy paradox states that learning and, accordingly, gaining digital literacy are social processes embedded in social settings, such as family and peers. The paradox surfaces "when older adults need to gain experience with ICTS to develop their skills, but they are apprehensive about using ICTS because they do not have the needed skills" (Schreurs and Quan-Haase, 2017, p. 362). Normally, seniors' social networks can reverse this lack of skills and/or technophobia by transforming them into active IT users. However, if some elders are convinced of their incapability to learn new digital tricks (self-fulfilling prophecy), they will not ask for help at all. In this case, the digital literacy paradox will not only grow, but it will be additionally reinforced. The "stereotype threat" goes hand in hand with the digital literacy paradox, as it describes a situation in which a person feels at risk of confirming a negative stereotype about one's own social group (Ivan and Schiau, 2016, p.340).

Finally, another common assertion in the literature is that older people demonstrate low selfefficacy (Czaja, et al. 2006), lack confidence or they feel too old (Juznic et al, 2006), computer anxiety (Van Dijk, 2005; Bozionelos, 2004), are incapable or even resistant to change (Cutler, 2005), internet laggards (Peacock S. and Künemund $\mathrm{H}_{.}, 2007$ ) and technophobic (Neves and Amaro, 2012) - a negative attitude toward modern technology in general. Following the words of Nimrod (2008, p.149-150): 
Table 5. Myths about older people's positioning in the digital realm.

Myth 1 The digital divide problem will solve itself. In the future, older people will use
ICTs without any trouble. This myth ignores three aspects: a. the progressive
nature of technical systems; b. the difficulties of attaining new knowledge in
old age, while technology keeps advancing; and c. the inevitable decline of
all functions in older people (i.e., perceptive, motor, and cognitive skills).

\begin{tabular}{ll}
\hline Myth $\mathbf{2}$ & $\begin{array}{l}\text { Older people have no interest in using ICTs because they cannot understand } \\
\text { the vast opportunities that they can offer. }\end{array}$ \\
\hline Myth $\mathbf{3}$ & $\begin{array}{l}\text { Older people do not value ICTs, which in their minds, are impractical or } \\
\text { useless devices. }\end{array}$ \\
\hline Myth $\mathbf{4}$ & $\begin{array}{l}\text { Older people lack specific physical capabilities (chiefly motor and perceptual } \\
\text { skills) needed in employing technology. }\end{array}$ \\
\hline Myth $\mathbf{5}$ & Older people cannot comprehend interactive ICTs. \\
\hline Myth $\mathbf{6}$ & Older people cannot learn new things. \\
\hline Note: The table was produced using material from Wandke, Sengpiel, and Sönksen (2012).
\end{tabular}

"technophobia refers to an exaggerated and unjustified fear, some authors considered it a pathological disorder and even argued that a case may be made for its inclusion among the problematic fears defined in the Diagnostic and Statistical Manual of Mental Disorders (DSM) - the standard classification of mental disorders (Brosnan, 2002; Thorpe and Brosnan, 2007)."

These representations repeatedly place older people either under the category of 'patient' or 'fragile-weak individuals', as technophobia is often considered a feature of older individuals. This predisposition brings also in mind the attached nexus between seniors and the discourse on biomedicalization, striving to control the seniors' bodies/ minds by restricting their levels of freedom.

Other negative social images, though different with regard to power, are expressed by the terms "laidback" and "needy"- the latter is worse than the former. Based on the typology of Ferro et al. (2011, p.8), "laidback" people have the intellectual capacity to learn how to use technology and acquire the necessary skills, but they are either unmotivated or unaware of the potential benefits that they can gain from digital technologies. For this reason, they often demonstrate the very basic use of the internet i.e. information search and email exchange. The "needy" are powerless and require the help and interventions of policymakers to change their mentality and habits. Even if older people are willing to use the internet in their daily life, they usually lack the basic IT skills and cultural background to battle the initial inertia and employ technology in meaningful ways (Ferro et al. 2011, p.8).

\section{Positive social images: Seniors pictured as Silver-surfers or athletes (strong in power) ver- sus older people with borrowed access (not so strong in power)}

On the other extreme, the current literature reports the case of "silver surfers", for describing proficient users of technology (Gorard and Selwyn, 2008). The silver surfers often share specific socio-demographic characteristics. In the Australian context (Russell et al. 2008), silver surfers were not only more confident and competent in using ICT, but also of a higher socioeconomic status (i.e., married, home-owning, English-speaking women and men in good health). Silver-surfers also appear to subscribe more to broadband internet (Choudrie et al., 2010). At this point, it must be noted that in some countries, the silver surfer's image is a tangible reality for the majority of older people, while in other, less digitally advanced countries it continues to be a far-reached dream- since the diffusion curve is not achieved for all and particularly for older people. An illustrative case is Greece, where people aged 65 and above are more than 11 times less likely to be online compared to the overall population (Niehaves and Plattfaut, 2014, p.709).

Selwyn et al. (2003, p. 562), mention that the silver surfer's image is "a popular but nebulous description of the confident and competent older ICT user". In our view, the silver-surfer image constitutes a positive stereotype amplifying the real digital skills of older people. In general, positive stereotypes are unrealistic, not borne out by a high number of individuals, and are aligned, again, with the rhetoric of successful aging (Bengtson and Settersten, 2016, p. 15) and its 'twin theoretical brother', the active aging discourse. In his research, Selwyn (2004, p. 380) found that older people's computer use is usually of a basic level and focused on specific tasks, like word processing, keeping in contact with others and generally teaching themselves about using the computer. As a matter of fact, older people access their computers at home and if support is available to them, it derives from family and close relations (Selwyn, 2004, p.380).

The silver-surfer image overlooks the 'middlerange' categories of older users of digital technologies by focusing exclusively on sketching the two extremes: older people as non-users of technology versus advanced users or otherwise silver surfers. These simplified and binary representations of older people do not capture by any means the complexity of the grey digital divide problem. It is reported from the current literature that digital users exhibit more diversity in their IT performance (Brandtzæg et al. 2011) by being "sporadic" users exhibiting occasional and infrequent use of Internet services, "entertain- 
Table 6. The four types of social images of older people and IT usage.

\begin{tabular}{|c|c|c|}
\hline & Positive social image & Negative social image \\
\hline $\begin{array}{l}\text { Strong in terms } \\
\text { of power }\end{array}$ & Silver surfers, "athletes" & $\begin{array}{l}\text { The "laidback" are older people, who are reluctant to use digital } \\
\text { technologies but have the necessary intellectual capacity to } \\
\text { acquire IT skills on their own. They usually lack sufficient } \\
\text { incentives in order to get involved with technology. }\end{array}$ \\
\hline
\end{tabular}

\begin{tabular}{|c|c|c|}
\hline $\begin{array}{l}\text { Weak in terms } \\
\text { of power }\end{array}$ & $\begin{array}{l}\text { Older people with "borrowed } \\
\text { access" to digital technologies }\end{array}$ & $\begin{array}{l}\text { Technophobic, non-users, want-nots, digitally backward/internet } \\
\text { laggards, digital immigrants, needy, or even worse unaware of } \\
\text { their digital condition. }\end{array}$ \\
\hline
\end{tabular}

Source: The author in combination with the work of Ferro et al (2011).

ment users", who employ Internet radio, TV, and download games or music, "instrumental users", who prefer to perform goal-oriented activities on the Internet, such as e-banking and "advanced users" who use the e-services and all the benefits of the Internet. Age and access unfailingly predict sporadic users (older age/low access), instrumental users (older age/medium access), entertainment users (younger age/high access), and advanced users (younger age/high access), while the effect size varied from country to country (Brandtzæg et al. 2011, p.133).

The existing silver-surfers are also a tangible confirmation of the "Matthew effect" which, according to Van Dijk (2005, p.96), "has its basis in current societal and technological tendencies of differentiation". The effect suggests that those who have more resources and good positions in society also have a considerable advantage in comparison to the less fortunate members of society. This considerable advantage of the previously mentioned individuals is maintained and, as happens in the case of the digitization of our societies, social inequalities have been reinforced (Van Djik, 2005; Fuchs, 2008; Steyaert and Gould, 2009 and Helsper, 2012).

Another positive and powerful image of older people is that of the "athletes". Based on the typology of Ferro et al. (2011, p.8), these individuals are technophiles, early adopters of technology receiving pleasure, and other benefits from technology. Athletes extensively use the internet in both their professional as well as their private daily life and they try to keep up to date their digital skills. This means that older people in this category usually invest time, money, and energy in order to not become digital laggards. Again, it is easier for those with higher socioeconomic status to maintain the previous digital lifestyle, provided that they are not confronted with serious health issues.

A milder stance compared to the above over-positive image is that of "borrowed access", which means receiving external help from someone capable of using digital technologies. RenelandForsman (2018, p.341) supports that "Being non- digitally competent is not considered being dependent, however, although individuals' ability to be an actively participating citizen making free lifestyle choice is restricted". Interestingly, it has been shown that many individuals may not feel excluded due to their differences in usage patterns or digital skills, but they are subject to phenomena of exclusion since they diverge from the dominant norm of society (Mariën and Prodnik, 2014). Hence, it is probable that older adults are ignorant as regards their current digital/social status.

To summarize, the aforementioned descriptions of older people probably do not constitute an exhaustive list of older user profiles (Table 6).

\section{A discussion on senior (non) digital users and policy intervention}

In pace with the rapid digitalization of our societies, individuals, including older people must engage more in the digital world, at least, in advanced societies, and keep their digital behavior and patterns active. This means that the active aging rhetoric is silently transplanted in the digital space under the form of "e-aging", by becoming the dominant norm in several highly digitalized societies with an abundant number of silversurfers. "E-aging" is a term that we invented to describe the continuous efforts that older people should make in order to keep up with technological changes and to remain digitally active in the cyber-space for a longer period. A striking example is Sweden, where most activities are done electronically for all, especially with regard to the country's public and health-related services (cf. Digitaliseringskommissionen, 2015)

Given the vast penetration of digital technologies, it has been quite often suggested that the digital divide and, consequently, the grey digital divide will close by itself as people become further involved with technology during their working life: "Disparities in access and skills based on age will disappear over time" (Kavanaugh and Patterson, 2002, p.342). This paper certainly does not hold such an optimistic view. It could be older people will upgrade their skills in the near future, but then again we should keep in mind that technology is in a ceaseless spin and new technological 
tools and applications require a constant update of seniors' digital knowledge.

Acquiring and preserving digital knowledge in the future will take the form of a life-long learning process, where every generation will have to fight a different struggle to keep in pace with the technological changes both in the workforce and in their retirement life (if retirement as a concept is still in place). Thus, we expect that the grey digital divide will respectively adopt a chameleon-like behavior and will add more digital anxieties to the generations to come. A new study (Van Deursen and Van Dijk, 2018) confirms our reservations while stating that the digital divide is a reality that is here to stay in terms of attitude, skills, type of use, and Internet outcomes as well as in terms of material access.

For the moment, the silver-surfer image is promoted as a desirable image. This image signifies a description of a single experience while there is a tendency to be projected to the entire group of seniors without taking into account the 'offliners' who in many occasions are old and/or very old people. As for the silver-surfer image and its relation to the aging process, it has become another way of transferring a number of youth traits to a group of older adults. These youth traits make older adults more attractive and up-to-date and somehow obscure the age denominator by prolonging the ageless and active midlife, similarly to the case of seniors, who are passionate about athletic activities (Vertinsky 2002). Without any doubt, this practice is aligned with the active aging rhetoric which is promoted in Europe and focuses on the preservation of body/mind activity for as long as possible. However, this rhetoric ignores that at some point older people will not be able to be engaged in society and the digital world, as well.

Silver-surfers tend to compare their skills with those of others, whether younger or of the same age (Quan-Haase et al., 2018). This informal competition could potentially lead certain seniors to stigmatize their peers, who prefer to act in line with their age, as it was discovered in the case of veteran athletes (Wheaton, 2017, p. 112). In this fashion, a new kind of internal, grey digital-social divide could appear between the old, digitally active silver-surfers, who demonstrate similar digital behavior to younger people and the old adults, who choose not to assume the digital patterns of younger individuals, either because they cannot afford this behavior or they are not interested in technology and prefer to do things the 'old way' like sending wishing cards instead of e-mails.

In the future, the 'new excluded' individuals will be those unable to understand and monitor the digital world at a satisfactory level. As a consequence, they are the ones to pay the economic and social price for not staying connected. In light of this, the welfare state and other authorities should find ways to include older people in the digital era. The profile of older digital users provides a first flavor regarding the immediate policy priorities. Policy-makers must pay closer attention to older people who are named as technophobic, non-users, want-nots, digitally backward/internet laggards, digital immigrants, needy and unaware of their digital condition, because they are weak in terms of power and at the same time, they carry a negative social image. This should be a state responsibility since these older people do not have the necessary knowledge to participate in the digital society, while they wish to. However, it is hard to say that older people who dislike or are not interested in technology have to be left behind without any state support. If this stance is taken, then we speak about a punitive state that punishes those who demonstrate a certain digital identity against the usage of digital technologies.

The next group of older people is the laidback, who despite their less negative description, have the necessary qualifications to become active members of the digital world. This group should be further informed (for instance through information campaigns) about the benefits of digitalization and must be persuaded to use digital tools in their daily life. For the moment, it seems that the laidback prefer to opt-out from the benefits of the digital realm. A similar path follows the older people with borrowed access who choose to access technology through an intermediary, which on many occasions is the family. Borrowed access is bigger in welfare states where the family has an important role in the lives of older people; while it can be problematic in countries (see for instance the Scandinavian countries) where family is not having such a dominant and intervening role into the seniors' lives. Despite their apparent limitations, the older people of this category demonstrate a positive image.

Older people with borrowed access are more likely to recognize the advantages of digital technologies but they do not have the IT literacy to move to the upper level, namely the silversurfer category. This 'confidence injection' may occur through targeted actions of the policymakers (for instance through learning courses), which will promote digital knowledge given that these older people wish to take up the technology. Older people who belong to this category are difficult to be discovered and thus they are almost completely left out of state assistance schemes, especially if they do not take action by demanding further assistance. The same applies 
to the group of laidback, with the only difference that they do not have the advantage of using an intermediary for participating in the digital world.

To finish, the most problematic category that was impossible to place within the above table was the e-disengaged individuals (Olphert W. and Damodaran L. 2013). Those individuals were digital users of technology but for some reason (usually health matters and not only) stopped using it. For this category, the policymakers have to find alternative ways, which will be based on human contact and assistance in later life. Human contact can be supported if some of the physical channels of communication are kept open for those who cannot anymore pursue the status of a digital silver surfer or a more modest version of it. Another solution for older people with mobility problems or other health matters is the assignment of a public employee (borrowed access), who is going to be responsible for the completion of their digital affairs, especially when the family is absent or it doesn't care.

Under any circumstances, it is crucial for seniors to be able to freely express their issues with digital disengagement to their relatives, close friends, or public workers in order to receive proper assistance. This help might be of paramount importance, when seniors interact with public and health authorities, using digital tools. Special 'borrowed access' services ought to be designed for those wishing to disconnect from the digital world and acquire the status of a 'digitally disengaged person' rather than a 'user status' -particularly in countries where most public-affair procedures are conducted online (see Sweden).

\section{LimitATIONS}

As in every research, there are some limitations to this study that ought to be taken into consideration. The usage of specific inclusion and exclusion criteria narrows down the eligible articles. Another limitation is that additional databases could have been used in order to capture a greater number of papers. Notwithstanding these issues, the article contributes to the academic debate on the representations of older people while using digital technologies. The policy-makers should discover new ways in order to bring older people into the digital era, especially today that the digitalization wave touches upon sensitive policy areas such as welfare and health services.

\section{Conclusion}

In this article, we described the grey digital divide for older people and we touched on the basic digital users' categories associated with older people (typology). ICTs and the internet are an open window of opportunity (Kingdon, 1995) for the senior population if they wish to 'open' it and particularly those who remain active after retirement and are willing to experiment, fulfill their dreams, and acquire new, stimulating knowledge (i.e. positive aging, Blaikie, 1999). Older people can utilize digital technologies in various ways in order to improve their quality of life, independence, and communication opportunities. This also applies to their interactions with the welfare state and health agencies, as these constitute important services for the current and future wellbeing of the silver generation.

When seen from a more skeptical viewpoint, the diffusion of digital (welfare) technologies can also be used as a pretext for transferring further responsibilities on older peoples' shoulders under the umbrella of active aging and neoliberal ideas. This allocation of new responsibilities and the individualization of risks will more likely be the case for the overall population. However, older people encounter even greater challenges in this respect. Older people usually face a higher risk of being or feeling social isolation and loneliness, in the absence of social support (Wenger, 1997, p.312) they might experience "cyberostracism" which refers to "any intended or perceived ostracism in communication modes other than faceto-face" (Williams, Cheung, and Choi, 2000, p.750); they encounter a drop in some of their cognitive abilities (Slegers et al., 2009; Hawthorn, 2008; Bussolo, Koettl, and Sinnott, 2015) and socioemotional skills (Bussolo, Koettl, and Sinnott, 2015) along with other unavertable health problems related to the aging process such as disabilities. This adverse situation can lead older people to digital exclusion or withdrawal but again as Schirmer and Michailakis (2018, p.85) pinpoint:

"While physical illness and disability contributes to the exclusion of older people from functionally diffuse collectivities or prevents them from inclusion, one could argue that it enables or facilitates their inclusion in the systems of medicine and help in as patients or clients."

The previous quote shows that exclusion is not absolute in life and someone can be both included and excluded at the same time. In another study (We et al, 2015, p.199) was found that ICT-related products, such as robotics, smart home technology, assistive communication devices, and sensors for social alarms often exhibit a "stigmatizing symbolism" that might stop older people from adopting them.

To conclude, the grey digital divide in relation to digital technologies is still a matter of concern for policy-makers and society as a whole since it affects several seniors and particularly those of old and/or very old age who, among other things, tends gradually to disengage from society. Policy-makers should emphasize primarily on those 
who lack the necessary digital skills and miss the remarkable opportunities offered by the digital revolution. This becomes a more urgent call due to the existence of a rapidly aging population and the ever-growing need for delivering a high quality of e-services for all. The challenge for welfare states today is to preserve their traditional role of responsiveness to meet the needs of every old person and to listen carefully to the expressed concerns of this group, even if the digitally illiterate older people turn out to be the minority. Only then, can one speak of having attained the "no-one-slips-through-the-net" goal or the goal of aging with dignity against homogenization phenomena (i.e. a one-size digital suit for all). As research indicates "measures to ensure accessibility to electronic communication need to be individually adaptable" (Borg et al. 2015, p.560).

\section{Acknowledgements}

The author would like to express her gratitude to Panayiota Tsatsou for her very useful insights and my supervisors, Joachim Åström, Agneta Blom and Martin Karlsson for their overall support and guidance.

\section{References}

Anderson, M., and Perrin, A. (2017). Tech adoption climbs among older adults. Washington, DC: Pew Research Center. Retrieved from: http://www. pewinternet.org/2017/05/17/techadoption-climbsamong-older-adults/

Arksey, H. and O'Malley, L. (2005). Scoping studies: towards a methodological framework. International Journal of Social Research Methodology, 8(1), 19-32. https://doi.org/10.1080/1364557032000119616

Beimborn M., Kadi S., Köberer N., Mühleck M. and Spindler M. (2016). Focusing on the Human: Interdisciplinary Reflections on Ageing and Technology. In E. Domínguez-Rué and L. Nierling (Eds) Ageing and Technology. Perspectives from the Social Sciences. Transcript Verlag.

Bengtson, L. V., and Settersten, A. R. (2016). Handbook on theories of ageing (3edition). New York: Springer Publishing Company.

Blaikie, A. (1999). Ageing \& popular culture. Cambridge: Cambridge University Press.

Bozionelos, N. (2004). Socio-economic background and computer use: the role of computer anxiety and computer experience in their relationship. Int. J. Hum.-Comput. Stud, 61 (5), 725-746. http:// dx.doi.org/10.1016/j.ijhcs.2004.07.001

Borg, J., Lantz, A. \& Gulliksen, J. (2015). Universal Access in the Information Society, 14(4), 547-562. https://doi.org/10.1007/s10209-014-0351-6

Brandtzæg, P. B., Heim, J. and Karahasanović, A. (2011). Understanding the new digital divide. International Journal of Human-Computer Studies, 69(3), 123 138. https://doi.org/10.1016/j.ijhcs.2010.11.004

Breit, E., and Salomon R. (2015). Making the Technological Transition - Citizens' Encounters with Digital Pension Services. Social Policy \& Administration 49 (3), 299-315. https://doi.org/10.1111/spol.12093

Bussolo, M., J. Koettl, and Sinnott E. (2015). Golden Aging: Prospects for Healthy, Active and Prosperous Aging in Europe and Central Asia. Washington, DC: World Bank.

Bygstad B. and Lanestedt G. (2017). Expectations and realities in welfare technologies: A Comparative study of Japan and Norway. Transforming Government: People, Process and Policy, 11(2), 286-303. https://doi.org/10.1108/TG-09-2016-0057

Choudrie, J., Grey, S. and Tsitsianis, N. (2010). Evalu- ating the digital divide: the silver surfer's perspective. Electronic Government: An International Journal, 7(2), 148-167. https://doi.org/10.1504/ EG.2010.030925

Comunello, F., Ardevol, M., Mulargia, S. and Belotti, F. (2016). Women, youth and everything else. Media, Culture \& Society, 39(6), 798-815. https://doi. org/10.1177/0163443716674363

Cutler, S.J. (2005). Ageism and Technology. Generations, 29(3), 67-72.

Czaja, S. J., Charness, N., Fisk, A. D., Hertzog, C., Nair, S. N., Rogers, W. A. and Sharit, J. (2006). Factors predicting the use of technology: Findings from the center for research and education on aging and technology enhancement (create). Psychology and Aging, 21(2), 333-352. http://dx.doi. org/10.1037/0882-7974.21.2.333

Demunter C. (2006). How skilled are Europeans in using the computers and the Internet? Stat Focus 17, 1-8.

Digitaliseringskommissionen. (2015). Om Sverige i framtiden - en antologi om digitaliseringens möjligheter [On the future in Sweden - an anthology on the opportunities in digitalization]. Report from Digitaliseringskommissionen. SOU 2015:65. Stockholm: Fritzes.

Eynon, R. and Helsper, E. (2011). Adults learning online: Digital choice and/or digital exclusion? New Media \& Society, 13(4), 534-551. https://doi. org/10.1177/1461444810374789

Ferro, E., Helbig N. C, and Gil-Garcia R. (2011). The role of IT literacy in defining digital divide policy needs. Government Information Quarterly, 28 (1), 3-10. https://doi.org/10.1016/j.giq.2010.05.007

Friemel, T.N. (2016). The digital divide has grown old: Determinants of a digital divide among seniors. New media \& society, 18(2), 313-331. https://doi. org/10.1177/1461444814538648

From, D-M. (2015). With a little help from a machine: Welfare Technology and Sustainable Health Promotion. Journal of Transdisciplinary Environmental Studies, 14(2), 52-64. Retrieved from: https://forskning.ruc.dk/da/publications/with-a-little-help-froma-machine-welfare-technology-and-sustaina

Fuchs, C. (2008). Internet and Society: Social Theory in the Information Age. Routledge: New York, NY, London.

Gilleard, C. and Higgs, P. (2008). Internet use and the digital divide in the English longitudinal study of ageing. European Journal of Ageing, 5, 233-239. https://doi.org/10.1007/s10433-008-0083-7

Gorard, S. and Selwyn, N. (2008). The myth of the Silver Surfer. Adults Learning, 19(5), 28-30. 
Granjon, F. (2009). Les inégalités numériques et la reconnaissance sociale. Des usages populaires de l'informatique connectée. Les cahiers du numérique, 1 (5), 19-44. https://doi.org/10.3166/ LCN.5.1.19-44

Gunkel, D. J. (2003). Second Thoughts: Toward a Critique of the Digital Divide. New Media \& Society, 5(4), 499-522. https://doi. org/10.1177/146144480354003

Hardey, M. and Loader, B. (2009). The informatization of welfare: Older people and the role of digital services. British Journal of Social Work, 39(4), 657 -69. https://doi.org/10.1093/bjsw/bcp024

Hargittai, E. (2002). Second-level digital divide: Differences in people's online skills. First Monday, 7(4). https://doi.org/10.5210/fm.v7i4.942

Hawthorn, R. (2008). ICT and the over 50s: overcoming barriers to employment and training advice. Retrieved from:

https://secure.toolkitfiles.co.uk/clients/29820/sitedata/ Branded\%20Publications/ictoverfifties.pdf

Helsper J. (2012). A Corresponding Fields Model for the Links between Social and Digital Exclusion. Communication Theory, 22(4), 403- 426. https://doi. org/10.1111/j.1468-2885.2012.01416.x

Hines, A. H., Nelson, A., and Tu, T. L. N. (2001). Hidden circuits. In A. Nelson, T. L. N. Tu, and A. H. Hines (Eds.), Technicolor. New York: New York University Press.

Ivan, L., and Schiau, I. (2016, July). Experiencing Computer Anxiety Later in Life: The Role of Stereotype Threat. In J. Zhou \& G. Salvendy (eds.), Human Aspects of IT for the Aged Populations, PART I Design for Aging, International Conference on Human Aspects of IT for the Aged Population (339-349). Volume 9755 of the series Lecture Notes in Computer Science. Springer International Publishing. Switzerland: Springer. Retrieved from: http://link.springer. com/chapter/10.1007/978-3-319-39943-0_33

Juznic, P., Blazic, M., Mercun, T. and Plestenjak, B. (2006). Who says that old dogs cannot learn new tricks? New Library World, 107(7-8), 332-345.

Katz, S. (2000). Busy Bodies: Activity, aging, and the management of everyday life. Journal of Aging Studies, 14(2), 135-152. https://doi.org/10.1016/ S0890-4065(00)80008-0

Katz, S. (2005). Cultural ageing: Life course, lifestyle and senior worlds. Peterborough, Canada: Broadwood.

Kavanaugh, A.L. and Patterson, S.J. (2002). The impact of community computer networks on social capital and community in Blacksburg. In: Wellman, B. and Haythornthwaite, C. (Eds), The Internet in Everyday Life (325-344). Malden, MA, and Oxford: Blackwell.

Kingdon, J. W. (1995). Agendas, Alternatives and Public Policies. London: Longman.

Levac, D., Colquhoun, H. and O'Brien, K.K. (2010). Scoping studies: advancing the methodology. Implementation Sci 5(69), 1-9. https://doi. org/10.1186/1748-5908-5-69

Lipsky M. (1980). Street-Level Bureaucracy: Dilemmas of the Individual in Public Services. Russell Sage Foundation.

Loges, W.E. and Jung J. Y. (2001). Exploring the Digital Divide, Internet Connectedness and Age. Com- munication Research, 28(4), 536-562. https://doi. org/10.1177/009365001028004007

Lüders, M. and Gjevjon, R.E. (2017). Being old in an always-on culture: Older people's perceptions and experiences of online communication. The Information Society, 33(2), 64-75. https://doi.org/10.108 0/01972243.2016.1271070

Mariën, I. and Prodnik, J. (2014). Digital inclusion and user (dis)empowerment: A critical perspective. Info, 16(6), 35-47. https://doi.org/10.1108/info-07-2014-0030

Martinez-Pecino R., Matos A. D. and Silva P. (2013). Portuguese older people and the Internet: Interaction, uses, motivations, and obstacles. Communications, 38(4), 331-346. https://doi.org/10.1515/ commun-2013-0020

Merton K. R. (1948). The Self-Fulfilling Prophecy. Antioch Review, 8(2), 193-210. https://doi. org/10.2307/4609267

Millward, P. (2003). The 'grey digital divide': Perception, exclusion and barriers of access to the Internet for older people. First Monday, 8(7). https://doi. org/10.5210/fm.v8i7.1066

Milioni, D. L., Doudaki, V., and Demertzis, N. (2014). Youth, ethnicity, and a 'reverse digital divide': A study of internet use in a divided country. Convergence-the International Journal of Research into New Media Technologies, 20(3), 316-336. https:// doi.org/10.1177/1354856513517366

Morris A. and Brading H. (2007). E-literacy and the grey digital divide: a review with recommendations. Journal of Information Literacy, 1(3), 13-28. https:// doi.org/10.11645/1.3.14

Morris, A., Goodman, J., and Brading, H. (2007). Internet use and non-use: views of older users. Universal Access in Information Society 6, 43-57. https:// doi.org/10.1007/s10209-006-0057-5

National Telecommunications and Information Administration, U.S. Department of Commerce. (1998). Falling through the net II: New Data on the Digital Divide. Retrieved from: https://www.ntia.doc.gov/ report/1998/falling-through-net-ii-new-data-digital-divide.

National Telecommunications and Information Administration, U.S. Department of Commerce. (1999). Falling through the net: Defining the digital divide. Washington, D.C. Retrieved from: http://www.ntia. doc.gov/report/1999/falling-through-net-definingdigital-divide.

Neves BB. and Amaro, F. (2012). Too old for technology? How the elderly of Lisbon use and perceive ICT. The Journal of Community Informatics. 8(1)

Neves, B., Amaro, F. and Fonseca, J. (2013). Coming of (old) age in the digital age: ICT usage and nonusage among older adults. Sociological Research Online, 18(2). https://doi.org/10.5153/sro.2998

Niehaves, B. and Plattfaut, R. (2014). Internet adoption by the elderly: employing IS technology acceptance theories for understanding the age-related digital divide. European Journal of Information Systems, 23(6), 708-726. https://doi.org/10.1057/ ejis.2013.19

Norris, P. (2001). Digital divide?: Civic engagement, information poverty, and the Internet worldwide. Cambridge: Cambridge University Press. 


\section{Portrait of older (non) users of digital technologies}

Olphert W. and Damodaran L. (2013). Older people and digital disengagement: a fourth digital divide? Gerontology, 59, 564 - 570. https://doi. org/10.1159/000353630

Östlund, B., Olander, E., Jonsson, O. and Frennert, S. (2015). STS-inspired design to meet the challenges of modern aging. Welfare technology as a tool to promote user-driven innovations or another way to keep older users hostage? Technological Forecasting and Social Change, 93, 82-90. https://doi. org/10.1016/j.techfore.2014.04.012

Peacock S. and Künemund H. (2007). Senior citizens and Internet technology Reasons and correlates of access versus non-access in a European comparative perspective. Eur. J. Ageing, 4, 191-200. https:// doi.org/10.1007/s10433-007-0067-z

Percival, J. and Hanson, J. (2006). Big brother or brave new world? Telecare and its implications for older people's independence and social inclusion. Critical Social Policy, 26(4), 888-909. https://doi. org/10.1177/0261018306068480

Prensky, Marc (2009). H. Sapiens Digital: From Digital Immigrants and Digital Natives to Digital Wisdom," Innovate: Journal of Online Education, 5(3). Retrieved from: https://nsuworks.nova.edu/innovate/ vol5/iss $3 / 1$

Quan-Haase A., Mo G.Y and Wellman B. (2017). Connected seniors: how older adults in East York exchange social support online and offline. Information, Communication \& Society, 20(7), 967-983. https://doi.org/10.1080/1369118X.2017.1305428

Quan-Haase, A., Williams, C., Kicevski, M., Elueze, I., and Wellman, B. (2018). Dividing the Grey Divide: Deconstructing Myths About Older Adults' Online Activities, Skills, and Attitudes. American Behavioral Scientist, 62(9), 1207-1228. https://doi. org/10.1177/0002764218777572

Reneland-Forsman, L. (2018). 'Borrowed access' - the struggle of older persons for digital participation. International Journal of Lifelong Education, 37(3), 333-344. https://doi.org/10.1080/02601370.2018.1 473516

Rittel J.W.H. and Webber M.M. (1973). Dilemmas in a General Theory of Planning. Policy Sciences, 4(2), 155-169.

Roberts, S. (2010). The Fictions, Facts and Future of Older People and Technology. Report of the International Longevity Centre - UK (ILC-UK), 1-14. Retrieved from: https://ilcuk.org.uk/the-fictions-factsand-future-of-older-people-and-technology/

Russell C., Campbell A. and Hughes I. (2008). Ageing, social capital and the Internet: findings from an exploratory study of Australian 'silver surfers'. Australasian Journal on Ageing, 27(2), 78-82. https:// doi.org/10.1111/j.1741-6612.2008.00284.x

Scheerder A., Van Deursen, A. and Van Dijk J. (2017). Determinants of Internet skills, uses and outcomes. A systematic review of the second- and third-level digital divide. Telematics and Informatics, 34(8), 1607-1624. https://doi.org/10.1016/j. tele.2017.07.007

Schneider, A. and Ingram, H. (1993). Social Construction of Target Populations: Implications for Politics and Policy. The American Political Science Review,
87(2), 334-347. https://doi.org/10.2307/2939044

Schreurs, K., Quan-Haase, A. and Martin, K. (2017). Problematizing the Digital Literacy Paradox in the Context of Older Adults' ICT Use: Aging, Media Discourse, and Self-Determination. Canadian Journal of Communication, 42(2). https://doi. org/10.22230/cjc.2017v42n2a3130

Schirmer, W., \& Michailakis, D. (2018). Inclusion/exclusion as the missing link: A Luhmannian analysis of loneliness among older people. Systems Research and Behavioral Science, 35, 76-89. https://doi. org/10.1002/sres.2441

Selwyn N. (2004). The information aged: A qualitative study of older adults' use of information and communications technology. Journal of Aging Studies, 18, 369-384. https://doi.org/10.1016/j.jaging.2004.06.008

Selwyn N., Gorard S., Furlong J. and Madden L. (2003). Older adults' use of information and communications technology in everyday life. Ageing \& Society, 23, 561-582. https://doi.org/10.1017/ S0144686X03001302

Servon, L.J. (2002). Bridging the Digital Divide: Technology, Community, and Public Policy. Malden, MA, and Oxford: Blackwell.

Siren A. and Knudsen S.G. (2017). Older Adults and Emerging Digital Service Delivery: A Mixed Methods Study on Information and Communications Technology Use, Skills, and Attitudes. J. Aging Soc. Policy, 29(1), 35-50. https://doi.org/10.1080/08959 420.2016.1187036

Slegers, K., Van Boxtel, M. and Jolles, J. (2009). The efficiency of using everyday technological devices by older adults: The role of cognitive functions. Ageing and Society, 29(2), 309-325. https://doi. org/10.1017/S0144686X08007629

Steyaert, J. and Gould, N. (2009). Social Work and the Changing Face of the Digital Divide. British Journal of Social Work, 39(4), 740 - 753. http://dx.doi.org/ bcp022

The Swedes and the Internet 2017 summary. Internetstiftelsen. Retrieved from: https://2017.svenskarnaochinternet.se/the-swedes-and-the-internet2017-summary/

Tsatsou, P. (2011). Digital divides revisited: what is new about divides and their research? Media, Culture \& Society, 33(2), 317-331. https://doi. org/10.1177/0163443710393865

Tsatsou, P., Youngs, G. and Watt, C. (2017). Literacy and identity links forging digital inclusion? Critical reflections and signposts from a qualitative study. In J. Choudrie, S. Kurnia and P. Tsatsou (Eds.) Innovative ICT-enabled Services and Social Inclusion. London: Routledge.

Van Dijk, J. (2005). The Deepening Divide. Inequality in the Information Society. Thousand Oaks, London, and New Delhi: Sage Publications.

Van Dijk, J. A. G. M. (2006). Digital divide research, achievements and shortcomings. Poetics, 34(4-5), 221235. https://doi.org/10.1016/j.poetic.2006.05.004

Van Dijk, J. (2008). Digital Divide in Europe. In A. Chadwick, and P. Howard (Eds.), The Routledge handbook of Internet politics (288-304). London and New York: Routledge. 


\section{Portrait of older (non) users of digital technologies}

Van Deursen A. and Helsper, E. (2015a). The Third-Level Digital Divide: Who Benefits Most from Being Online?, in (ed.) Communication and Information Technologies Annual (Studies in Media and Communications, Volume $10(29$ - 52). .Emerald Group Publishing Limited.

Van Deursen, A., and Helsper, E. (2015b). A nuanced understanding of Internet use and nonuse amongst older adults. European Journal of Communication, 30(2), 171-187. https://doi. org/10.1177/0267323115578059

Van Deursen, A.J.A.M. and Van Dijk, J.A.G.M. (2018). The first-level digital divide shifts from inequalities in physical access to inequalities in material access. New Media \& Society, 21(2), 354-375. https://doi. org/10.1177/1461444818797082

Van Dyk S. (2014). The appraisal of difference: Critical gerontology and the active-ageing-paradigm. Journal of Aging Studies, 31, 93-103. https://doi. org/10.1016/j.jaging.2014.08.008

Vertinsky, P. (2002). Sporting Women in the Public Gaze: Shattering the Master Narrative of Aging Female Bodies. Canadian Woman Studies, 21 (3), 58-63.

Wandke H., Sengpiel M. and Sönksen M. (2012). Myths about Older People's Use of Information and Communication Technology. Gerontology, 58, 564570. https://doi.org/10.1159/000339104
Webster, J., Watson, R.T. (2002). Analyzing the past to prepare for the future: writing a literature review. MIS Q. 26(2), xiii-xxiii

Wei, K. K., Teo, H.H., Chan, H.C. (2011). Conceptualizing and testing a social cognitive model of the digital divide. Information Systems Research, 22(1), 170-187. https://doi.org/10.1287/isre.1090.0273

Wenger G.C. (1997). Social networks and the prediction of elderly people at risk. Aging \& Mental Health, 1(4), 311-320. https://doi. org/10.1080/13607869757001

Wheaton, B. (2017). Surfing through the life-course: silver surfers' negotiation of ageing. Annals of Leisure Research, 20(1), 96-116. https://doi.org/10.1080/11 745398.2016.1167610

Williams KP, Cheung CKT, Choi W. (2000). Cyberostricism: effects of being ignored over the internet. Journal of Personality and Social Psychology, 79(5), 748-762. https://doi. org/10.1037//0022-3514.79.5.748

Wu, Y. H., Damnée, S., Kerhervé, H., Ware, C., and Rigaud, A. S. (2015). Bridging the digital divide in older adults: a study from an initiative to inform older adults about new technologies. Clinical interventions in aging, 10, 193-200. https://doi. org/10.2147/CIA.S72399 